\title{
Utilização de documentação ortodôntica na identificação humana*
}

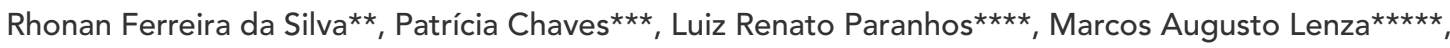 \\ Eduardo Daruge Júnior ${ }^{\star \star \star \star \star \star ~}$
}

\section{Resumo}

Objetivo: o objetivo deste trabalho é relatar um caso pericial onde um indivíduo encontrado carbonizado foi identificado utilizando-se as informações presentes na sua documentação ortodôntica. Métodos: um indivíduo do sexo masculino foi encontrado carbonizado no interior de um automóvel. Após a realização dos exames periciais no local, exames necroscópicos e radiográficos no Instituto Médico-Legal, identificou-se que a vítima utilizava aparelho ortodôntico fixo, possuía dentes supranumerários nas quatro hemiarcadas, terceiros molares semi-inclusos e restaurações de amálgama em determinadas faces de diversos dentes. Como os tecidos moles do indivíduo apresentavam-se bastante destruídos, uma identificação pela análise das impressões digitais tornou-se inviável. Após a entrega da documentação ortodôntica pela família, foi feita a análise do prontuário clínico, radiografias, fotografias intra e extrabucais e modelos de gesso - confrontando-se essas informações com as obtidas anteriormente. Resultado e Conclusões: o confronto odontolegal revelou 20 pontos concordantes do exame necroscópico e da documentação ortodôntica, permitindo a determinação de uma correlação positiva entre o cadáver examinado e a identidade da pessoa desaparecida, tornando-se desnecessária a realização de outros exames para a identificação da vítima (exame de DNA).

Palavras-chave: Antropologia forense. Odontologia Legal. Ortodontia.

\section{INTRODUÇÃO}

A Ortodontia pode ser definida como sendo a especialidade que tem como objetivo a prevenção, a supervisão e a orientação do desenvolvimento do aparelho mastigatório e a correção das estruturas dentofaciais, incluindo as condições que requeiram movimentação dentária, bem como a harmonização da face no complexo maxilomandibular ${ }^{4}$.

Em virtude da complexidade dos casos e do considerável tempo envolvido no tratamento ortodôntico, o especialista dessa área precisa produzir uma variedade de documentos odontológicos, fundamentais para a realização do planejamento e execução desse tipo de tratamento. Essa documentação normalmente é composta pelo prontuário odontológico, que pode ser definido como sendo um documento de natureza abrangente que reúne informações pertinentes à identificação do

* Trabalho realizado para a obtenção do título de especialista em Ortodontia pela FO-UFG.

** Mestre em Odontologia Legal FOP-UNICAMP. Professor de Odontologia Legal FO-UFG e UNIP-GO. Perito Criminal Oficial da Polícia Técnico-Científica (GO).

*** Mestre em Clínica Odontológica Integrada/Dentística FOP/UNICAMP. Especialista em Ortodontia FO-UFG.

**** Doutor em Biologia Buco-Dental - FOP/UNICAMP/Piracicaba. Professor Titular do Programa de Pós-Graduação em Odontologia área de concentração Ortodontia, da UMESP/São Bernardo do Campo.

***** Doutor em Ortodontia pela Universidade de Nebraska (EUA). Professor Titular de Ortodontia FO-UFG.

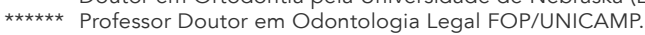


paciente, anamnese, questionário de saúde, exame físico geral, exames extra e intrabucal, plano de tratamento escolhido e autorizado pelo paciente e execução do tratamento. $\mathrm{O}$ prontuário também é utilizado como meio de arquivo para os exames complementares produzidos em função do tratamento ortodôntico (radiografias, modelos de gesso, fotografias, traçados ortodônticos, dentre outros documentos específicos).

No Brasil, o profissional da Odontologia tem o dever ético de manter adequadamente arquivada toda a documentação odontológica produzida em função do tratamento de seus pacientes, conforme preconiza o Artigo $5^{\circ}$ (VIII) do Código de Ética Odontológica ${ }^{3}$. Clinicamente, o arquivamento da documentação odontológica permite que o ortodontista tenha a possibilidade de acompanhar, em qualquer época, o desenvolvimento dos tratamentos em andamento e os casos já finalizados. Em Odontologia Legal, a importância desse arquivamento está relacionada tanto com as questões ligadas à defesa profissional, em casos de processos contra cirurgiões-dentistas ${ }^{8}$, quanto aos casos de identificação de corpos esqueletizados, putrefeitos ou carbonizados ${ }^{11,12,13}$.

Considerando-se a responsabilidade profissional do ortodontista no exercício da profissão, associada à riqueza de informações presentes na documentação ortodôntica, o presente trabalho tem como objetivo relatar um caso pericial onde um indivíduo encontrado carbonizado foi identificado utilizandose as informações presentes numa radiografia panorâmica e em fotografias intrabucais produzidas em decorrência de tratamento ortodôntico.

\section{RELATO DO CASO}

Em agosto de 2006, um indivíduo do sexo masculino foi encontrado carbonizado no interior de um automóvel. Após a realização dos exames periciais no local, o corpo foi removido ao Instituto Médico-Legal da região para que fossem efetuados os exames necroscópicos de rotina, como a determinação da causa da morte, identificação do instrumento ou meio que a produziu e, se possível, estabelecer a identidade da vítima.

Em virtude da friabilidade dos tecidos duros remanescentes, exacerbada pela presença de zonas de calcinação, optou-se pela enucleação maxilomandibular para que as características odontológicas presentes nas arcadas dentárias pudessem ser melhor examinadas. Mesmo tomando-se os devidos cuidados durante a necropsia odontolegal, parte da estruturas situadas na região anterior da mandíbula não resistiu à manipulação dos tecidos, perdendo parcialmente a sua integridade. Os exames necroscópico e radiográfico dessas peças revelaram a presença de diversos eventos odontológicos com grande importância pericial, tais como o uso de aparelho ortodôntico fixo (Fig. 1), dentes supranumerários nas quatro hemiarcadas, terceiros molares semi-inclusos e restaurações de amálgama em diversos dentes e faces (Fig. 2, 3).

Paralelamente ao exame cadavérico, as investigações policiais avançaram, encontrando informações sobre a provável vítima, com características antropológicas compatíveis com as presentes no cadáver. Como os seus tecidos moles apresentavam-se bastante destruídos, uma identificação pela análise das impressões digitais tornou-se inviável. Desse modo, os familiares dessa pessoa desaparecida foram orientados a procurar qualquer tipo de documentação médica, odontológica ou fotográfica que pudesse subsidiar a identificação do indivíduo.

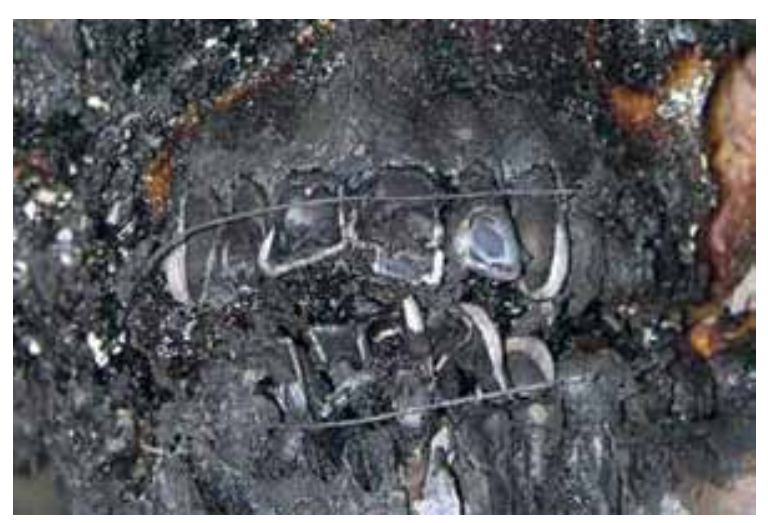

FIGURA 1 - Dentes anteriores carbonizados com ausência de braquetes (perdidos juntamente com o esmalte vestibular), e presença do fio ortodôntico. 

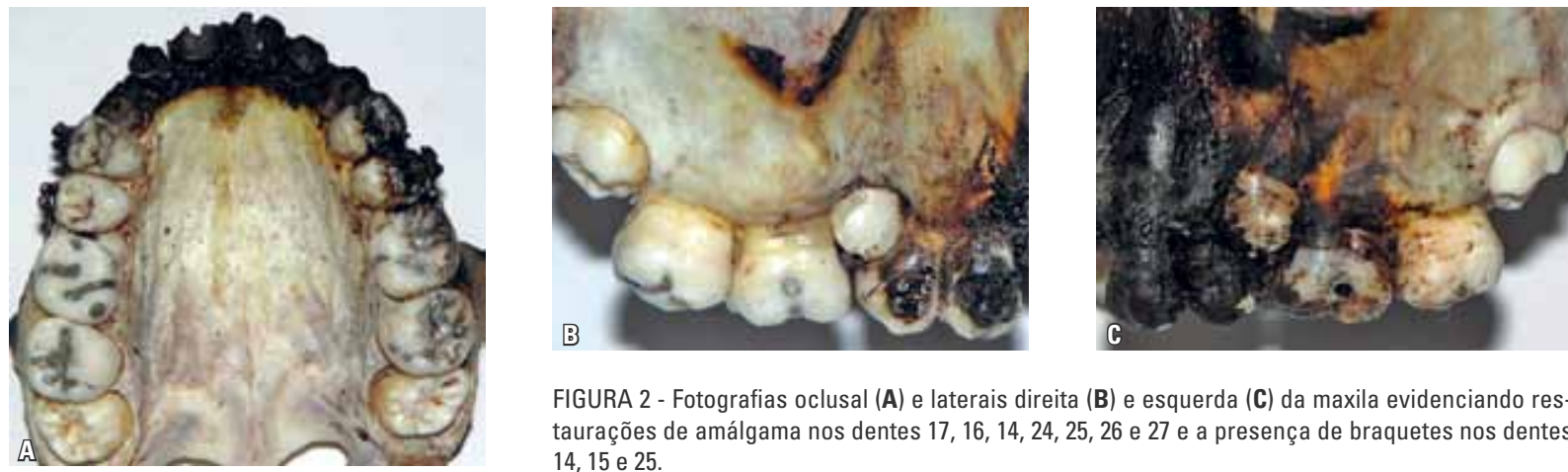

FIGURA 2 - Fotografias oclusal (A) e laterais direita (B) e esquerda (C) da maxila evidenciando restaurações de amálgama nos dentes 17, 16, 14, 24, 25, 26 e 27 e a presença de braquetes nos dentes 14,15 e 25 .
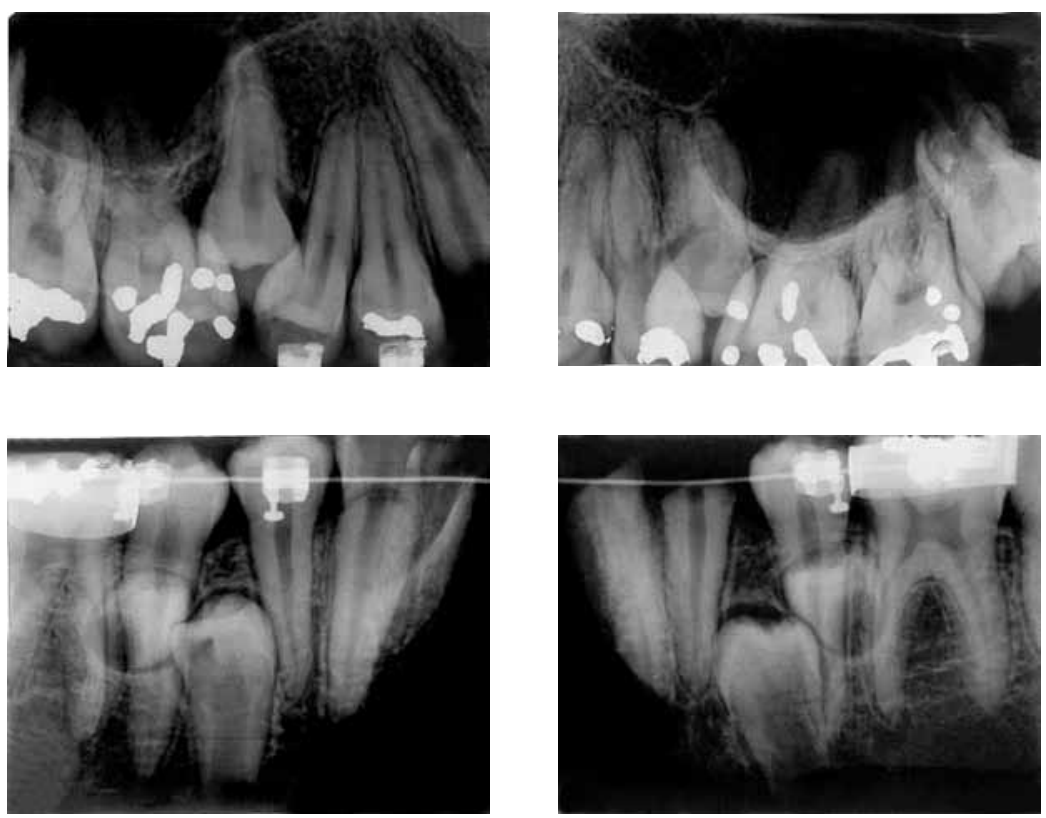

FIGURA 3 - Radiografias pós-morte, onde se observam dentes supranumerários nas arcadas dentárias superior e inferior, alguns braquetes e bandas nos molares inferiores.

O resultado dessa procura culminou na informação de que o indivíduo desaparecido estava sob tratamento ortodôntico e toda a sua documentação clínica foi requisitada. A documentação entregue para exame era composta de um prontuário clínico, uma radiografia panorâmica (Fig. 4), uma telerradiografia, 5 fotografias intrabucais (Fig. 5), 3 fotografias extrabucais, uma solicitação de extração de dentes supranumerários, um laudo radiográfico e um par de modelos de gesso, sendo essas peças documentais datadas do ano de 2005.

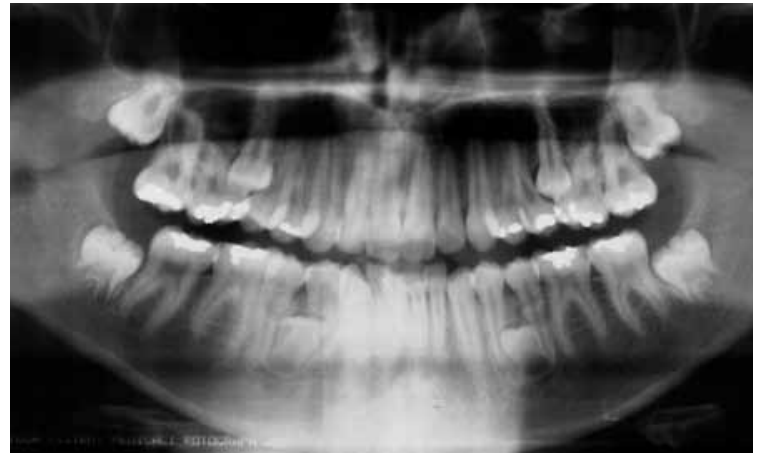

FIGURA 4 - Radiografia panorâmica utilizada no tratamento ortodôntico (2005). 

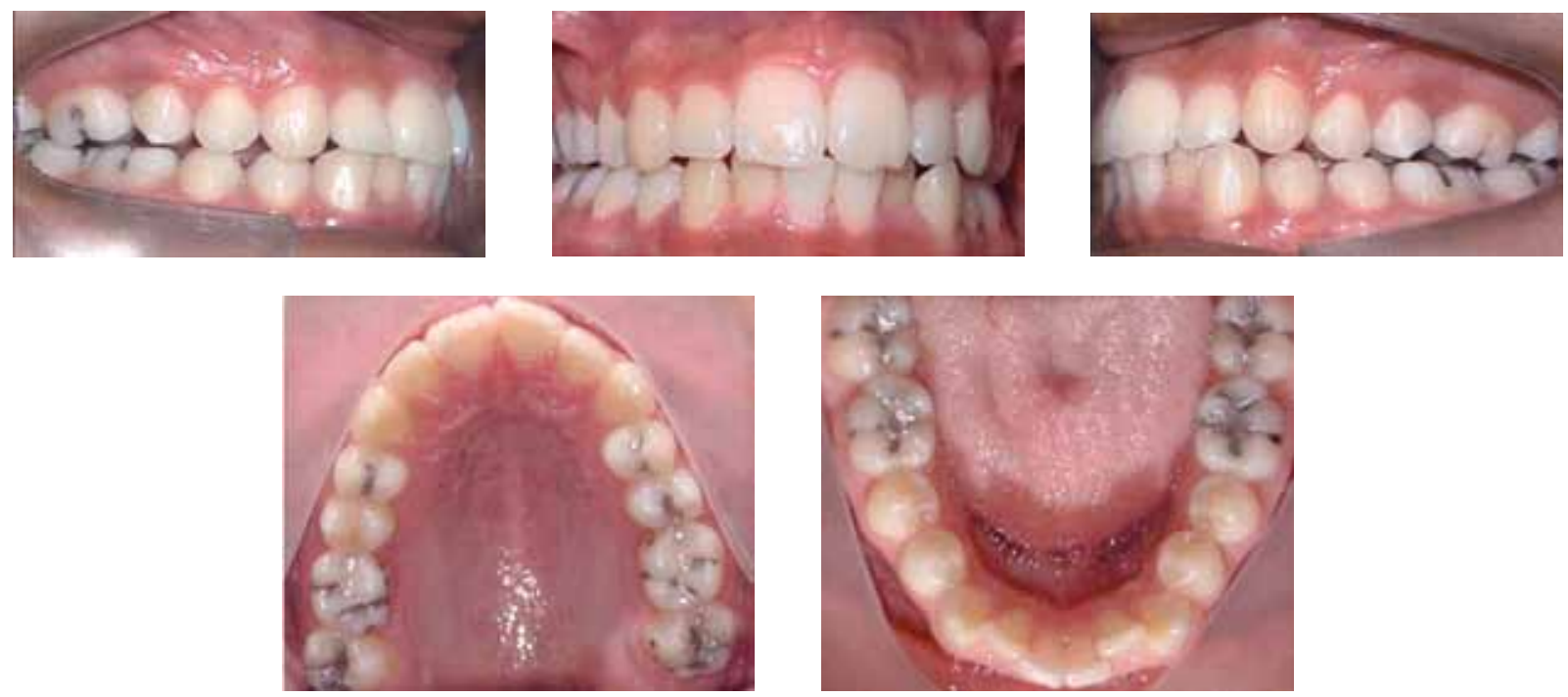

FIGURA 5 - Fotografias intrabucais realizadas para tratamento ortodôntico (2005).

Todas as informações e características odontológicas presentes na referida documentação ortodôntica foram agrupadas num único odontograma.

\section{DISCUSSÃO}

A literatura pericial relata diversos casos onde indivíduos carbonizados, esqueletizados ou em decomposição foram identificados pela análise das particularidades odontológicas ${ }^{5,6}$, podendo essa técnica estar associada a outros métodos de identificação humana ${ }^{2}$. Os bons resultados obtidos por essa técnica advêm da considerável resistência dos dentes e dos materiais odontológicos à ação do fogo $^{7}$, associada às informações presentes na documentação produzida em função do atendimento odontológico (prontuário odontológico, radiografias odontológicas e fotografias).

A identificação odontolegal pode ser classificada como uma metodologia comparativa para a determinação da identidade de um indivíduo e, didaticamente, é dividida em três etapas: exame das arcadas dentárias do cadáver, exame da documentação odontológica e confronto odontolegal ${ }^{9}$. Na primeira etapa são anotadas todas as particularidades presentes nas arcadas dentárias do cadáver, relacionadas com a presença e/ou ausência dentárias, restaurações (faces e materiais), próteses, tratamentos endodônticos, patologias e anomalias, dentre outros aspectos. No exame da documentação odontológica são coletadas todas as informações pertinentes ao tratamento efetuado ou planejado, anotadas pelo clínico no prontuário odontológico, associando-as às informações analisadas nos exames complementares (radiografias, fotografias, modelos, dentre outros). A última etapa é a comparação das informações obtidas nas duas fases anteriores, considerando o mesmo ponto de referência (face, dente ou hemiarcada) e tendo como base uma análise qualitativa e quantitativa das particularidades odontológicas evidenciadas (Fig. 6).

No presente caso, observou-se, por meio do confronto odontolegal, que um total de 20 pontos relevantes de confronto foram identificados, 

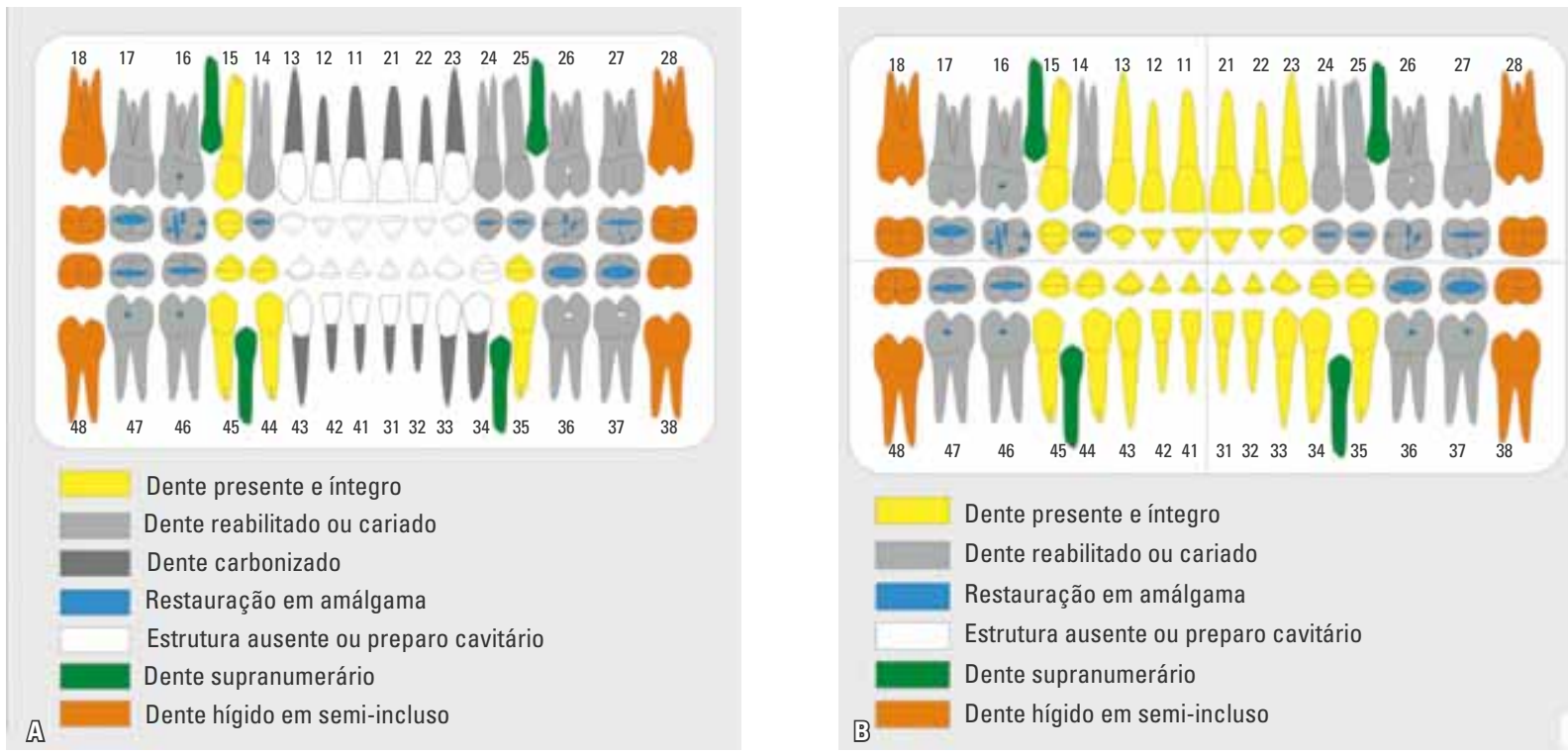

FIGURA 6 - A) Odontograma feito a partir dos exames necroscópicos e radiográficos do cadáver; e B) outro odontograma contendo a representação das informações extraídas da documentação ortodôntica.

relacionados com a presença dos dentes supranumerários situados entre os dentes 15 e 16, 25 e 26, 34 e 35, e 44 e 45 (conforme notação dentária preconizada pela Federação Dentária Internacional, FDI); além da morfologia e localização das restaurações de amálgama presentes na maioria dos dentes posteriores. Esses pontos convergentes de confronto permitiram a determinação de uma correlação positiva entre o cadáver examinado e a identidade da pessoa desaparecida, tornando-se desnecessária a realização de outros exames para a identificação da vítima (exame de DNA). É válido salientar que o exame genético propicia a obtenção de resultados extremamente confiáveis, mas fica aquém do exame odontolegal quando são comparados o custo, o tempo e a logística necessários para a realização da técnica ${ }^{10}$.

Cabe ressaltar que a identificação positiva desse indivíduo foi possível mediante a obtenção da documentação relacionada ao tratamento or- todôntico da pessoa desaparecida. A radiografia panorâmica e as fotografias utilizadas no planejamento ortodôntico foram obtidas mediante emprego de técnicas corretas, sem distorções ou com a nitidez comprometida, permitindo que aspectos qualitativos fossem analisados. É por esse motivo que não se pode estabelecer um número mínimo de pontos para que um indivíduo seja identificado positivamente pela técnica odontolegal, variando a quantidade de pontos convergentes conforme cada caso ${ }^{1}$.

\section{CONCLUSÃO}

É imprescindível que os cirurgiões-dentistas tenham consciência da importância do correto preenchimento do prontuário odontológico e da adequada produção e arquivamento das demais peças que compõem a documentação odontológica, uma vez que, além da importância clínica, elas podem fornecer esclarecimentos relevantes à Justiça. 


\title{
Use of orthodontic records in human identification
}

\begin{abstract}
Objective: This study describes a forensic case of incinerated remains of a man that were identified using information found in his orthodontic records. Methods: Incinerated remains of a man were found inside a car. After forensic crime scene investigation and postmortem and radiographic exams in the Forensic Department, forensic experts found that the victim had a fixed orthodontic appliance, supernumerary teeth in all quadrants, partially erupted third molars and amalgam restorations in some surfaces of several teeth. As the individual's soft tissues were substantially destroyed, identification using fingerprints was not the ideal choice. After orthodontic records were handed in by the family, his clinical chart, radiographs, intra- and extraoral photographs and impressions were analyzed, and these data were compared with previously collected information. Results and Conclusions: Forensic dentistry examination revealed 20 concordant points in specimen examination and orthodontic records, which enabled the establishment of a positive correlation between the cadaver under examination and the missing person and eliminated the need for further analyses (DNA tests) to identify the victim.
\end{abstract}

Keywords: Forensic anthropology. Forensic dentistry. Orthodontics.

\section{REFERÊNCIAS}

1. Acharya AB, Taylor JA. Are a minimum number of concordant matches needed to establish identity in forensic odontology? J Forensic Odontostomatol. 2003 Jun;21(1):6-13

2. Bilge Y, Kedici PS, Alakoç YD, Ulküer KU, Ilkyaz YY. The identification of a dismembered human body: a multidisciplinary approach. Forensic Sci Int. 2003 Nov 26;137(2-3):141-6.

3. Conselho Federal de Odontologia (Brasil). Código de ética odontológica: aprovado pela resolução CFO n42. Rio de Janeiro. 2003. [Acesso em: 2006 nov 6]. Disponível em: $<$ http://www.cfo.org.br>

4. Conselho Federal de Odontologia (Brasil). Consolidação das normas para procedimentos nos conselhos de Odontologia: aprovada pela resolução CFO n 63. Rio de Janeiro, 2005. [Acesso em: 2006 nov 6]. Disponível em: <http://www.cfo.org.br>.

5. Goodman NR, Himmelberger LK. Identifying skeletal remains found in a sewer. J Am Dent Assoc. 2002 Nov;133(11):1508-13.

6. Marks MK, Bennett JL, Wilson OL. Digital video image capture in establishing positive identification. J Forensic Sci. 1997 May;42(3):492-5.

7. Muller M, Berytrand MF, Quatrehomme G, Bolla M, Rocca JP. Macroscopic and microscopic aspects of incinerated teeth. J Forensic Odontostomatol. 1998 Jun;16(1):1-7.

8. Ramos DIA, Daruge Júnior E, Daruge E, Antunes FCM, Meléndez BVC, Francesquín JL, et al. Transposición dental y sus implicaciones eticas y legais. Rev ADM. 2005 septoct;62(5):185-90.

9. Rothwell BR. Principles of dental identification. Dent Clin North Am. 2001 Apr;45(2):253-70.

10. Silva RF, Pereira SDR, Daruge E, Daruge Júnior E, Francesquini JL. A confiabilidade do exame odontolegal na identificação humana. Robrac. 2004;13(35):46-50.
11. Silva RF, Cruz BVM, Daruge Júnior E, Daruge E, Francesquini JL. La importancia de la documentación odontológica en la identificación humana. Acta Odontol Venez. 2005 ago;43(2):67-74

12. Silva RF, Pereira SDR, Mendes SDS, Marinho DEA, Daruge Júnior E. Radiografias odontológicas: fonte de informação para a identificação humana. Odontologia Clín Científ. 2006; 5(3):239-42.

13. Silva RF, Prado MM, Barbieri AA, Daruge Júnior E. Utilização de registros odontológicos para identificação humana. RSBO. 2009;6(1):95-9.

Enviado em: abril de 2007

Revisado e aceito: fevereiro de 2009

Endereço para correspondência

Rhonan Ferreira da Silva

Av. Atílio Correia Lima,1223 - Cidade Jardim

CEP: 74.425-030 - Goiânia / GO

E-mail: rhonanfs@terra.com.br 